\title{
Analysis of the Fee-to-Tax Reform on Water Resources in China
}

\section{Zi-rui Chen ( $\nabla$ 827899406@qq.com )}

South China Normal University https://orcid.org/0000-0002-7647-2579

\section{Pu-yan Nie}

Guangdong University of Finance \& Economics

\section{Original article}

Keywords: Fee-to-Tax reform, Asymmetric duopoly, Water resource tax

Posted Date: April 6th, 2021

DOI: https://doi.org/10.21203/rs.3.rs-306845/v1

License: (a) (i) This work is licensed under a Creative Commons Attribution 4.0 International License. Read Full License 


\section{Analysis of the Fee-to-Tax reform on water resources in China}

Zi-rui Chen

Guangdong Academy of Social Science, Guangzhou, 510635, P.R. China

Pu-yan Nie

School of Finance, Institute of Guangdong Economy \& Social Development, Guangdong University of Finance \& Economics(GDUFE), Guangzhou, 510320, P.R. China.

Corresponding author:

Zi-rui Chen

Guangdong Academy of Social Science, Guangzhou, 510635, P.R. China.

E-mail: ziruichen25@gmail.com 


\begin{abstract}
Background: The Resource Tax Law has been officially implemented on September 1, 2020 in China. This law presents the "Fee-to-Tax" reform of water resources.

Methods: This article compares the effects of the "Fee-to-Tax" reform under an asymmetric duopoly with perfect information.

Results: First, an analysis when all firms simultaneously respond to the water resource policy is conducted. The mechanisms of the two policies are different: the water resource fee affects output by reducing market size, while the water resource tax reduces output by amplifying the weighted cost difference effects between companies. It is shown that the tax works better than the fee for eliminating backward production capacity. Then, a comparison of the situation when companies respond sequentially is carried out. When a low-cost firm is in the leading position, the collection of fees actually reduces the output difference, whereas the tax improves it. When a high-cost firm acts as a leader, the effects depend on the cost difference. When the cost difference between firms is small, the first-move advantage of high-cost firms dominates the cost advantages of low-cost firms. Therefore, a higher tax rate yields a smaller output difference.
\end{abstract}

Conclusions: When cost differences are relatively larger, the cost advantage of low-cost firms dominates the first-move advantage of high-cost firms. Therefore, the "Fee-to-Tax" reform provides some benefits to maintain the environmental development of some water-mining or related industries.

\title{
Key words: Fee-to-Tax reform; Asymmetric duopoly; Water resource tax
}

\section{Introduction}

On August 26, 2019, after the twelfth meeting of the Standing Committee of the Thirteenth National People's Congress, the Resource Tax Law was officially adopted and has been officially implemented on September 1, 2020. For the first time, the 
Resource Tax Law explicitly levies water resource taxes on a trial basis for industries and individuals who use surface water or groundwater. If a water resource tax is levied, then the collection of water resource fees will cease. China's water resources are very scarce, and the per capita water resources are only one-fourth of the world average. Water resources are unevenly distributed in space and time, and there are problems such as water pollution, waste, the excessive exploitation of groundwater, and weak citizen protection awareness. With the development of the construction of an ecological civilization, the importance of water resources to human society is constantly increasing; therefore, a general trend is to include water resources in the scope of resource tax collection.

China began collecting water resource fees in 1980. In 1988, China officially promulgated and implemented the "Water Law of the People's Republic of China", which explicitly included the collection of water resource fees into the legal scope. The collection of water resource fees has serious problems, such as multisector collection, low actual collection rates, and irregular use management. To promote the construction of resource-saving and environmentally friendly cities, increase citizens' awareness of water resource protection and water efficiency, and improve water resources, China has included water resources in the scope of resource tax collection.

Although country characteristics must necessarily shape practical policy advice, theory provides some fairly specific guidance. This paper aims to analyze the theoretical basis that underlies the Fee-to-Tax reformation of water resources.

The remainder of this paper is organized as follows. Section 2 provides a summary of the literature related to this topic. Section 3 introduces the model. The model is discussed in Section 4 when all firms simultaneously respond to the policy. An analysis of the model when not all firms respond simultaneously is carried out in Section 5. Finally, concluding remarks are presented in Section 6.

\section{Literature review}


When studying the effect of the reform of water resource fees and taxes, scholars hold different opinions. Mushtaq et al. (2008) questioned the effectiveness and feasibility of a water Fee-to-Tax reform and noted that this reform is likely to cause serious difficulties in agricultural production. Ma, Zhao and Ni (2018) indicated that tax reform is conducive to reducing not only arbitrary charges but also the burden on enterprises, and the collection and use of a water resource tax is more reasonable and transparent, which is helpful for the state to control the source and use of the water resource tax and to reduce corruption. Some researchers established the Computable General Equilibrium Model (CGE) of the economy with water as an explicit factor of production. Qin et al. (2012) used the CGE model to assess the economic impact of water pricing in China. Li et al. (2019) calculated a reasonable tax rate of water resources in Yunan Province with the CGE model. Beyond these studies, there are few articles on the economic principles of water resource tax-fee shifting.

To avoid increasing the corporate tax burden, a general rule is presented that the tax fee after the reform equals the original water resource fee in the Fee-to-Tax reform. In this particular situation, the collection of water resource fees can be seen as a special type of unit tax before the Fee-to-Tax reform. Considering this, the model that studies ad valorem and unit taxes can be adapted to analyze the effect of the Fee-to-Tax reform on water resources.

The comparison between these two types of taxes is a classic topic that has been the subject of ongoing discussion and development in public finance (Skeath, 1992; Blackorby and Murty, 2006; Vetter, 2017). The study of differentiated duopolies or oligopolies was developed by Dixit (1979), Singh and Vives (1984), Häckner (1999) and other scholars. Wang and Zhao (2007) compared the welfare effects of cost reductions in differentiated Bertrand and Cournot oligopolies but did not take taxation into account. It was indicated that in asymmetric and differentiated oligopolies, unit taxation could be welfare-superior to ad valorem taxation if the goods are sufficiently differentiated under either Cournot or Bertrand competition (X. H. Wang \& Zhao, 
2009). Lapan and Hennessy (2011) extended the analysis to multimarket oligopolies. For a linear demand system, it is also demonstrated that the marginal cost of public funds for ad valorem taxes is generally lower than that for unit taxes (Häckner \& Herzing, 2016). Arguably, policy designers favor the use of ad valorem taxes over unit taxes in oligopolies. However, the anticompetitive effects of the two taxes on firms' strategic interactions favor unit taxes over ad valorem taxes (Vetter, 2014). Given decreasing returns to scale, an ad valorem tax regime unambiguously Pareto dominates a unit tax regime (Hoffmann \& Runkel, 2016). Griffith and Nesheim et al. (2018) noted that by considering the use of tax policy, utility is linear in the consumption of the outside good. A specific tax results in larger reductions than an ad valorem tax but at a greater cost to consumers.

The vast majority of applications focus on how these theories help us to explain economic situations in real life (Nie \& Chen, 2012; Nie, Wang, Chen, \& Chen, 2018; Tao, Wang, \& Yang, 2018). Such theories are also applied to discuss clean and dirty technology competition (Acemoglu, Akcigit, Hanley, \& Kerr, 2016; Chen, Nie, \& Wang, 2015), the impacts of subsidies and taxation (Chen, Wen, Wang, \& Nie, 2017; Golosov, Hassler, Krusell, \& Tsyvinski, 2014; C. Wang, Nie, Peng, \& Li, 2017; Yang, Nie, Liu, \& Shen, 2017; Dong, Wei, Ma, \& Li, 2018), and other related social economic issues (Bloch \& Demange, 2018; Fuest, Peichl, \& Siegloch, 2018; Z. Wang \& Wright, 2017).

In this paper, the model of ad valorem and unit taxes is further developed to study the effect of the Fee-to-Tax reform under an asymmetric duopoly by investigating the total outputs and the difference in the outputs in the two collection regimes.

\section{Model establishment}

By taking water resource policy into account, a duopoly model is adopted for the following study. In an industry, two asymmetric firms exist (the marginal production 
costs are different) that compete in quantity. For convenience, denote the two firms as $\{A, B\}$. The marginal costs of the two firms are constants, $c_{i}, i \in\{A, B\}$, which satisfies $c_{A}<c_{B}$. Assume that the two firms' outputs are $q_{i}, i \in\{A, B\}$ and that prices are $p_{i}, i \in\{A, B\}$. The inverse demand function satisfies

$$
p_{i}=\alpha-q_{i}-\gamma q_{j}, i, j \in\{A, B\}, i \neq j \text {. }
$$

In (1), $\alpha>0$ means that the market size and $\gamma \in[0,1]$ represent product substitutability. High product substitutability manifests in similar functions offered by the products of the two firms. A larger $\gamma$ means higher product substitutability; thus, in the extreme case, $\gamma=1$ indicates that the products of the two firms have the same function, whereas $\gamma=0$ means that each firm has a monopoly on a different product. This type of inverse demand function is widely adopted in economics and in industrial organizations (Chen, He, \& Paudel, 2018; Chen, Huang, Mishra, \& Wang, 2018). Considering the water resource policy, both firms' profits are listed as follows: $\pi_{i}=\left(p_{i}-c_{i}\right) q_{i}-T\left(\tau, p_{i} ; \kappa, q_{i}\right)$.

In (2), $\tau \geq 0$ is the collection rate based on price when the water resource fee is collected, and $\kappa \geq 0$ is the taxation rate according to the outputs when the water resource tax is collected (Lapan \& Hennessy, 2011). For (2), the term $\left(p_{i}-c_{i}\right) q_{i}$ is revenues, and $T\left(\tau, p_{i} ; \kappa, q_{i}\right)$ is payment for water resources. When the water resource fee is collected, $T=\kappa q_{i}$. When the water resource tax is collected, $T=\tau p_{i} q_{i}$. We do not consider subsidies and always assume the taxation intensity to be nonnegative. (1) and (2), along with the tax function and fee function, constitute the asymmetric duopoly model with water resource usage payments.

In the following section, the above model is used to analyze the effect of the Fee-to-Tax reform in the situation when all firms respond to the policy change 
simultaneously.

\section{Policy effect under Cournot equilibrium}

Assuming that all firms respond to the policy simultaneously, then the model is discussed under Cournot competition.

When the water resource fee is collected, function (2) is also concave, and the unique equilibrium is determined by the first-order optimal condition. The equilibrium is outlined by the following equations:

$\frac{\partial \pi_{i}}{\partial q_{i}}=\left(\alpha-\gamma q_{j}-2 q_{i}\right)-c_{i}-\kappa=0, i, j \in\{A, B\}, i \neq j$.

The equilibrium is

$q_{A}^{*, 1}=\frac{(2-\gamma)(\alpha-\kappa)-\left(2 c_{A}-\gamma c_{B}\right)}{\left(4-\gamma^{2}\right)}, q_{B}^{*, 1}=\frac{(2-\gamma)(\alpha-\kappa)-\left(2 c_{B}-\gamma c_{A}\right)}{\left(4-\gamma^{2}\right)}$.

When water resource fees are collected, both firms reduce outputs, and the two firms reduce output identically. The output gap and corresponding price and profits are

$$
\Delta q^{*, 2}=\frac{c_{B}-c_{A}}{(2-\gamma)}
$$

$$
\begin{aligned}
& p_{A}^{*, 1}=\frac{\alpha}{2+\gamma}+\frac{\kappa(1+\gamma)}{2+\gamma}+\frac{\left(2-\gamma^{2}\right) c_{A}+\gamma c_{B}}{\left(4-\gamma^{2}\right)}, \\
& p_{B}^{*, 1}=\frac{\alpha}{2+\gamma}+\frac{\kappa(1+\gamma)}{2+\gamma}+\frac{\left(2-\gamma^{2}\right) c_{B}+\gamma c_{A}}{\left(4-\gamma^{2}\right)}, \\
& \pi_{A}^{*, 1}=\left[\frac{(2-\gamma)(\alpha-\kappa)-\left(2 c_{A}-\gamma c_{B}\right)}{\left(4-\gamma^{2}\right)}\right]^{2}, \\
& \pi_{B}^{*, 1}=\left[\frac{(2-\gamma)(\alpha-\kappa)-\left(2 c_{B}-\gamma c_{A}\right)}{\left(4-\gamma^{2}\right)}\right]^{2} .
\end{aligned}
$$

Before the Fee-to-Tax reform, the water resource fee reduced the total outputs and producer's surplus. The corresponding price increases with the fee collection intensity. The output difference remains constant regardless of the amount of payment per unit, 
which means that such a policy places an identical effect on the outputs of the two firms. From (4), we have $\left|\frac{\partial q_{B}^{*, 1}}{\partial \kappa}\right|=\left|\frac{\partial q_{A}^{*, 1}}{\partial \kappa}\right|$. Therefore, it is also found that higher product substitutability yields a larger output gap.

When the water resource tax is collected, the payment is $T\left(\tau, p_{i} ; \kappa, q_{i}\right)=\tau p_{i} q_{i}$. Thus, the equilibrium is outlined by the following equations:

$$
\frac{\partial \pi_{i}}{\partial q_{i}}=(1-\tau)\left(\alpha-\gamma q_{j}-2 q_{i}\right)-c_{i}=0, i, j \in\{A, B\}, i \neq j .
$$

The equilibrium is

$$
q_{A}^{*, 2}=\frac{(2-\gamma)(1-\tau) \alpha-\left(2 c_{A}-\gamma c_{B}\right)}{\left(4-\gamma^{2}\right)(1-\tau)}, q_{B}^{*, 2}=\frac{(2-\gamma)(1-\tau) \alpha-\left(2 c_{B}-\gamma c_{A}\right)}{\left(4-\gamma^{2}\right)(1-\tau)} .
$$

According to function (9) and $c_{A}<c_{B}$, both firms reduce outputs under $2 c_{A}-\gamma c_{B}>0$. Moreover, when the cost difference is small, the high-efficiency firm reduces fewer outputs than the low-efficiency firm. Under $2 c_{A}-\gamma c_{B}<0$, the water resource tax improves the outputs of high-efficiency firms and reduces the outputs of low-efficiency firms. The output gap is

$$
\Delta q^{*, 2}=q_{A}^{*, 2}-q_{\mathrm{B}}^{*, 2}=\frac{c_{B}-c_{A}}{(2-\gamma)(1-\tau)} .
$$

The corresponding price and profits are given as follows:

$$
\begin{aligned}
& p_{A}^{*, 2}=\frac{\alpha}{2+\gamma}+\frac{\left(2-\gamma^{2}\right) c_{A}+\gamma c_{B}}{\left(4-\gamma^{2}\right)(1-\tau)}, p_{B}^{*, 2}=\frac{\alpha}{2+\gamma}+\frac{\left(2-\gamma^{2}\right) c_{B}+\gamma c_{A}}{\left(4-\gamma^{2}\right)(1-\tau)}, \\
& \pi_{A}^{*, 2}=(1-\tau)\left[\frac{(2-\gamma)(1-\tau) \alpha-\left(2 c_{A}-\gamma c_{B}\right)}{\left(4-\gamma^{2}\right)(1-\tau)}\right]^{2}, \\
& \pi_{B}^{*, 2}=(1-\tau)\left[\frac{(2-\gamma)(1-\tau) \alpha-\left(2 c_{B}-\gamma c_{A}\right)}{\left(4-\gamma^{2}\right)(1-\tau)}\right]^{2} .
\end{aligned}
$$


From (9), we have $\left|\frac{\partial q_{B}^{*, 2}}{\partial \tau}\right|>\left|\frac{\partial q_{A}^{*, 2}}{\partial \tau}\right|$. Therefore, the water resource tax has a greater effect on high-cost firms than on low-cost firms. Moreover, $\frac{\partial \Delta q^{*, 2}}{\partial \gamma}>0$. Higher product substitutability yields a larger output gap.

The above formulations are analyzed and summarized as follows. (1) The water resource tax reduces total outputs and increases the output gap. (2) With small cost differences, the water resource tax reduces the outputs and profits of both firms. (3) Under large cost differences, the water resource tax improves the outputs and profits of high-efficiency firms while reducing the outputs and profits of low-efficiency firms. Proof of these conclusions is shown in Appendix A.

\section{Effect of the "Fee-to-Tax" reform}

Based on the above analysis, we argue that the implementation of water resource taxes improves prices while reducing total output and product surplus. Higher taxes mean higher prices and lower outputs. The above equilibriums are next compared. We first define the cost difference combined with product substitutability: $2 c_{i}-\gamma c_{j}$ is the weighted cost difference.

Obviously, product substitutability increases the opponent's costs in the weighted cost difference. When $\gamma=0$, the opponent's costs have no effect on the firm's decisions. This definition reflects the interaction of both the opponent's costs and product substitutability. In practice, firms care much more about the above weighted cost difference than the cost difference.

Based on the above definition, we can intuitively draw the following conclusions. Under Cournot competition, collecting the water resource fee affects equilibrium by reducing the market size, while collecting the water resource tax affects equilibrium by amplifying the effects of the weighted cost difference. Both the water resource fee and tax affect the market equilibrium, and the affecting mechanisms differ. Water 
resource fees reduce the market size and then reduce firms' outputs and profits. To the contrary, collecting a tax amplifies the effects of the weighted cost difference and then affects the output difference and profits. The above conclusions capture the action mechanism of the different taxes.

When conducting the Fee-to-Tax reform, a general rule is that the amount of payment remains unchanged during the reform. Thus, a comparison of the outputs is conducted under this basic rule. That is,

$$
\begin{aligned}
& \tau p_{A}^{*, 2} q_{A}^{*, 2}+\tau p_{B}^{*, 2} q_{B}^{*, 2}=\tau\left[\frac{\alpha}{2+\gamma}+\frac{\left(2-\gamma^{2}\right) c_{A}+\gamma c_{B}}{\left(4-\gamma^{2}\right)(1-\tau)}\right] \frac{(2-\gamma)(1-\tau) \alpha-\left(2 c_{A}-\gamma c_{B}\right)}{\left(4-\gamma^{2}\right)(1-\tau)}+ \\
& \tau\left[\frac{\alpha}{2+\gamma}+\frac{\left(2-\gamma^{2}\right) c_{B}+\gamma c_{A}}{\left(4-\gamma^{2}\right)(1-\tau)}\right] \frac{(2-\gamma)(1-\tau) \alpha-\left(2 c_{B}-\gamma c_{A}\right)}{\left(4-\gamma^{2}\right)(1-\tau)}=\kappa\left(q_{A}^{*, 1}+q_{B}^{*, 1}\right) \\
& =\kappa \frac{2(\alpha-\kappa)-\left(c_{A}+c_{B}\right)}{(2+\gamma)}
\end{aligned}
$$

(13) is restated as

$$
\begin{aligned}
& \frac{\tau \alpha}{2+\gamma} \frac{2(1-\tau) \alpha-\left(c_{A}+c_{B}\right)}{(1-\tau)}+\tau \alpha \frac{\left(2-\gamma^{2}+\gamma\right)\left(c_{A}+c_{B}\right)}{\left(4-\gamma^{2}\right)(1-\tau)}-\tau\left[\frac{\left(2-\gamma^{2}\right) c_{A}+\gamma c_{B}}{\left(4-\gamma^{2}\right)(1-\tau)}\right] \frac{\left(2 c_{A}-\gamma c_{B}\right)}{(2-\gamma)(1-\tau)} \\
& -\tau\left[\frac{\left(2-\gamma^{2}\right) c_{B}+\gamma c_{A}}{\left(4-\gamma^{2}\right)(1-\tau)}\right] \frac{\left(2 c_{B}-\gamma c_{A}\right)}{(2-\gamma)(1-\tau)}=\kappa\left[2(\alpha-\kappa)-\left(c_{A}+c_{B}\right)\right] .
\end{aligned}
$$

For the output effects of the two types of policy, we have the following relationship:

$$
q_{A}^{*, 2}-q_{A}^{*, 1}=\frac{\kappa}{(2+\gamma)}-\frac{\tau\left(2 c_{A}-\gamma c_{B}\right)}{\left(4-\gamma^{2}\right)(1-\tau)}, q_{B}^{*, 2}-q_{B}^{*, 1}=\frac{\kappa}{(2+\gamma)}-\frac{\tau\left(2 c_{B}-\gamma c_{A}\right)}{\left(4-\gamma^{2}\right)(1-\tau)} .
$$

Under the fixed total amount of payment, we find that (1) the water resource fee does not change the output difference, while the water resource tax increases the output difference between the two firms. (2) $q_{A}^{*, 2}-q_{A}^{*, 1}>q_{B}^{*, 2}-q_{B}^{*, 1}$. (3) Under
$\frac{\kappa}{\tau} \leq \frac{\alpha}{2+\gamma}+\frac{\left(2-\gamma^{2}\right) c_{A}+\gamma c_{B}}{\left(4-\gamma^{2}\right)(1-\tau)}$, unit taxes yield more output than ad valorem taxes yield. 
Otherwise, unit taxes lead to fewer outputs than ad valorem taxes. Proof of these conclusions is presented in Appendix B.

Interestingly, the distinguishing effects on the output difference are the result of the two policies' action mechanisms. Such a tax affects the outputs by amplifying the effects of the weighted cost difference, while a fee affects the equilibrium by reducing the market size. According to (15), we immediately obtain $q_{A}^{*, 2}-q_{A}^{*, 1} \geq q_{B}^{*, 2}-q_{B}^{*, 1}$. Therefore, after the reform, it is more advantageous to phase out backward production capacity. Moreover, it is shown that $q_{A}^{*, 2}-q_{A}^{*, 1}>q_{B}^{*, 2}-q_{B}^{*, 1}$. This also demonstrates that high-cost firms experience a larger loss than low-cost firms experience.

For the price effect of the two types of policies, we further have the following formulation:

$p_{A}^{*, 2}-p_{A}^{*, 1}=\tau \frac{\left(2-\gamma^{2}\right) c_{A}+\gamma c_{B}}{\left(4-\gamma^{2}\right)(1-\tau)}-\frac{\kappa(1+\gamma)}{2+\gamma}, p_{B}^{*, 2}-p_{B}^{*, 1}=\tau \frac{\left(2-\gamma^{2}\right) c_{B}+\gamma c_{A}}{\left(4-\gamma^{2}\right)(1-\tau)}-\frac{\kappa(1+\gamma)}{2+\gamma}$

Function (16) indicates that $p_{A}^{*, 2}-p_{A}^{*, 1}<p_{B}^{*, 2}-p_{B}^{*, 1}$.

\section{Policy effect under Stackelberg equilibrium}

Assuming that not all firms respond to the policy synchronously, then the model is discussed under Stackelberg competition. We first address the case in which the low-cost firm plays the leading position, and the high-cost firm acts as a follower. Then, we consider the other case in which the high-cost firm leads, while the low-cost firm follows. Under Stackelberg competition, the analysis of prices and profits is similar to that under Cournot competition. Thus, in the following section, we mainly 
focus on outputs.

\subsection{Low-cost firm as a leader}

When a low-cost firm (firm $A$ ) is a leader, we first consider the follower to address the leader. The problem is solved by a backward induction approach.

By taking a backward induction approach, we immediately obtain the following equilibrium when the water fee is collected.

$$
\begin{aligned}
q_{A}^{* s, 1} & =\frac{(2-\gamma)(\alpha-\kappa)-\left(2 c_{A}-\gamma c_{B}\right)}{2\left(2-\gamma^{2}\right)}, \\
q_{B}^{*}, 1 & =\frac{\left(4-2 \gamma-\gamma^{2}\right)(\alpha-\kappa)-\left(4-\gamma^{2}\right) c_{B}+2 \gamma c_{A}}{4\left(2-\gamma^{2}\right)} .
\end{aligned}
$$

The output gap of the two firms is

$$
\left|q_{A}^{* s, 1}-q_{B}^{* s, 1}\right|=\frac{\gamma^{2}(\alpha-\kappa)-(4-2 \gamma) c_{A}+\left(4-\gamma^{2}+2 \gamma\right) c_{B}}{4\left(2-\gamma^{2}\right)} .
$$

Under Stackelberg competition, collecting the water resource fee affects the output gap, which is different from the result under Cournot competition. Moreover, $q_{A}^{* s, 1}>q_{B}^{*_{s, 1}}, q_{A}^{*_{s, 1}}>q_{A}^{*, 1}$, and $q_{B}^{*_{s, 1}}<q_{B}^{*, 1}$. After the Fee-to-Tax reform, the objective function is concave for the follower firm (firm $B$ ), and the first-order optimal condition uniquely determines its solution: $q_{B}=\frac{1}{2}\left(\alpha-\gamma q_{A}\right)-\frac{c_{B}}{2(1-\tau)}$. The objective function of firm $A$ is

$$
\pi_{A}=(1-\tau)\left[\alpha-q_{A}-\frac{\gamma}{2}\left(\alpha-\gamma q_{A}\right)+\frac{\gamma c_{B}}{2(1-\tau)}\right] q_{A}-c_{A} q_{A}
$$

(19) is concave, and the unique equilibrium is determined by the first-order optimal conditions as follows:

$\frac{\partial \pi_{A}}{\partial q_{A}}=(1-\tau)\left[\left(1-\frac{\gamma}{2}\right) \alpha-2\left(1-\frac{\gamma^{2}}{2}\right) q_{A}+\frac{\gamma c_{B}}{2(1-\tau)}\right]-c_{A}=0$

The equilibrium is given as follows. 


$$
\begin{aligned}
& q_{A}^{*_{s, 2}}=\frac{(2-\gamma)(1-\tau) \alpha-\left(2 c_{A}-\gamma c_{B}\right)}{2\left(2-\gamma^{2}\right)(1-\tau)}, \\
& q_{B}^{*_{s, 2}}=\frac{1}{2} \alpha-\frac{c_{B}}{2(1-\tau)}-\frac{\gamma}{2} \frac{(2-\gamma)(1-\tau) \alpha+\gamma c_{B}-2 c_{A}}{2\left(2-\gamma^{2}\right)(1-\tau)} \\
& =\frac{2\left(2-\gamma^{2}\right)(1-\tau) \alpha-2\left(2-\gamma^{2}\right) c_{B}-\left[(2-\gamma)(1-\tau) \gamma \alpha+\gamma^{2} c_{B}-2 \gamma c_{A}\right]}{4\left(2-\gamma^{2}\right)(1-\tau)} \\
& =\frac{\left(4-2 \gamma-\gamma^{2}\right)(1-\tau) \alpha-\left(4-\gamma^{2}\right) c_{B}+2 \gamma c_{A}}{4\left(2-\gamma^{2}\right)(1-\tau)} .
\end{aligned}
$$

Similarly, the output gap is

$$
\left|\Delta q^{*_{s, 2}}\right|=q_{A}^{*_{s, 2}}-q_{B}^{*_{s, 2}}=\frac{\gamma^{2}(1-\tau) \alpha+\left(4+2 \gamma-\gamma^{2}\right) c_{B}-(4+2 \gamma) c_{A}}{4\left(2-\gamma^{2}\right)(1-\tau)} .
$$

The corresponding price is

$$
p_{A}^{*_{S, 2}}=\frac{(2-\gamma) \alpha}{4}+\frac{2 c_{A}+\gamma c_{B}}{4(1-\tau)}, p_{B}^{*_{s, 2}}=\frac{\left(4-2 \gamma-\gamma^{2}\right) \alpha}{4\left(2-\gamma^{2}\right)}+\frac{\left(4-3 \gamma^{2}\right) c_{B}+2 \gamma c_{A}}{4\left(2-\gamma^{2}\right)(1-\tau)} \text {. }
$$

Based on the above analysis, we have the following conclusions. When firm $A$ acts as the leader, according to (18), the water resource fee reduces the output difference, while the water resource tax improves the output difference. In this situation, a larger water resource fee yields a lower output difference, while a larger tax rate causes a larger output difference. Based on the above conclusion, high-cost firms may prefer water resource fees, and low-cost firms may favor taxes.

In addition, under the Stackelberg game, $q_{A}^{*_{s, 2}}>q_{A}^{*, 2}, q_{B}^{*, 2}<q_{B}^{*, 2}$. Proof of these equations is shown in Appendix C. Thus, the output difference when not all firms respond simultaneously is larger than the output difference under the Cournot game. Accordingly, when low-cost firms respond first to the policy reform, these firms possess both cost and first-move advantages. These advantages yield larger output differences than those when firms act at the same time. In contrast, when firms do not respond simultaneously, the effects of the policy reform that supports the phasing out 
of backward production capacity are strengthened.

\subsection{High-cost firm as a leader}

When a high-cost firm (firm $B$ ) acts as a leader, the problem is also solved by a backward induction approach. We first consider the situation when the water resource fee was collected.

$$
\begin{aligned}
q_{B}^{*_{s, 3}} & =\frac{(2-\gamma)(\alpha-\kappa)-\left(2 c_{B}-\gamma c_{A}\right)}{2\left(2-\gamma^{2}\right)}, \\
q_{A}^{* s, 3} & =\frac{\left(4-2 \gamma-\gamma^{2}\right)(\alpha-\kappa)-\left(4-\gamma^{2}\right) c_{A}+2 \gamma c_{B}}{4\left(2-\gamma^{2}\right)} .
\end{aligned}
$$

The output gap is

$$
q_{A}^{* s, 3}-q_{B}^{* s, 3}=\frac{-\gamma^{2}(\alpha-\kappa)+(4+2 \gamma) c_{B}-\left(4-\gamma^{2}+2 \gamma\right) c_{A}}{4\left(2-\gamma^{2}\right)} .
$$

Similar conclusions to those drawn in Section 5.1 also hold. That is, $q_{B}^{* s, 1}<q_{B}^{*, 1}<q_{B}^{* s, 3}$, and $q_{A}^{*, s, 1}>q_{A}^{*, 1}>q_{A}^{*, 3,3}$. Moreover, a small cost difference between the two firms implies that $q_{A}^{* s, 3}<q_{B}^{*_{s, 3}}$, and a large cost difference indicates that $q_{A}^{*_{s, 3}}>q_{B}^{*_{s, 3}}$. Thus, we draw the following conclusion. When a high-cost firm acts as the leader, with a small cost difference, the first-move advantage of firm $B$ dominates the cost advantages of firm $A$. Therefore, for small cost differences, a higher tax rate yields a smaller output difference. When cost differences are relatively larger, the cost advantage of firm $A$ dominates the first-move advantage of firm $B$, and a higher fee rate yields larger output differences. In this way, the water resource fee promotes output differences. Moreover, the total outputs under the water resource fee satisfy the relationships

$$
\begin{aligned}
& q_{B}^{*_{s, 3}}+q_{A}^{*_{s, 3}}=\frac{\left(8-4 \gamma-\gamma^{2}\right)(\alpha-\kappa)-(4-2 \gamma) c_{B}-\left(4-\gamma^{2}-2 \gamma\right) c_{A}}{4\left(2-\gamma^{2}\right)}, \\
& q_{A}^{*_{s, 1}}+q_{B}^{*_{s, 1}}=\frac{\left(8-4 \gamma-\gamma^{2}\right)(\alpha-\kappa)-(4-2 \gamma) c_{A}-\left(4-\gamma^{2}-2 \gamma\right) c_{B}}{4\left(2-\gamma^{2}\right)} .
\end{aligned}
$$


Apparently, $q_{A}^{*_{s, 1}}+q_{B}^{*_{s, 1}}>q_{B}^{*_{s, 3}}+q_{A}^{*_{s, 3}}$. Similarly, we also have the relationship $q_{A}^{* s, 1}+q_{B}^{*_{s, 1}}>q_{B}^{*_{s, 3}}+q_{A}^{*_{s, 3}}>q_{A}^{*, 1}+q_{B}^{*, 1}$.

In the situation when the water resource tax is collected, for the follower firm (firm A), $q_{A}=\frac{1}{2}\left(\alpha-\gamma q_{B}\right)-\frac{c_{A}}{2(1-\tau)}$. The objective function of firm $B$ is $\pi_{B}=(1-\tau)\left[\alpha-q_{B}-\frac{\gamma}{2}\left(\alpha-\gamma q_{B}\right)+\frac{\gamma c_{A}}{2(1-\tau)}\right] q_{B}-c_{B} q_{B}$.

(26) is concave, and the unique equilibrium is determined by the first-order optimal conditions as follows: $\frac{\partial \pi_{B}}{\partial q_{B}}=0$.

The equilibrium is given as follows.

$q_{B}^{*_{s, 4}}=\frac{(2-\gamma)(1-\tau) \alpha-\left(2 c_{B}-\gamma c_{A}\right)}{2\left(2-\gamma^{2}\right)(1-\tau)}$,

$q_{A}^{* s, 4}=\frac{\left(4-2 \gamma-\gamma^{2}\right)(1-\tau) \alpha-\left(4-\gamma^{2}\right) c_{A}+2 \gamma c_{B}}{4\left(2-\gamma^{2}\right)(1-\tau)}$.

Similarly, the output gap is

$$
\Delta q^{*_{s, 4}}=q_{A}^{*_{s, 4}}-q_{B}^{*_{s, 4}}=\frac{-\gamma^{2}(1-\tau) \alpha-\left(4+2 \gamma-\gamma^{2}\right) c_{A}+(4+2 \gamma) c_{B}}{4\left(2-\gamma^{2}\right)(1-\tau)} .
$$

Based on (27), we have the relationships $q_{A}^{*_{s, 4}}<q_{A}^{*, 2}<q_{A}^{*_{s, 2}}$ and $q_{B}^{*_{s, 4}}>q_{B}^{*, 2}>q_{B}^{*_{s, 2}}$. The corresponding price is

$$
p_{B}^{* *_{s, 4}}=\frac{(2-\gamma) \alpha}{4}+\frac{2 c_{B}+\gamma c_{A}}{4(1-\tau)}, p_{A}^{*_{s, 4}}=\frac{\left(4-2 \gamma-\gamma^{2}\right) \alpha}{4\left(2-\gamma^{2}\right)}+\frac{\left(4-3 \gamma^{2}\right) c_{A}+2 \gamma c_{B}}{4\left(2-\gamma^{2}\right)(1-\tau)} .
$$

Based on the above analysis, we obtain the following conclusions:

$8 q_{A}^{*_{s, 4}}<q_{A}^{*, 2}<q_{A}^{*_{s, 2}}, q_{B}^{*_{s, 4}}>q_{B}^{*, 2}>q_{B}^{*_{s, 2}}$ and $q_{A}^{*, 2}+q_{B}^{*, 2}<q_{A}^{*_{s, 4}}+q_{B}^{*_{s, 4}}<q_{A}^{*_{s, 2}}+q_{B}^{*_{s, 2}}$. Proof of these equations is presented in Appendix D. Under the Stackelberg game, firm $A$ possesses both a cost advantage and second-move disadvantage. This disadvantage 
yields a smaller output difference than that under the Cournot game. Furthermore, the total outputs when the low-cost firm plays a leading position are higher than the total outputs when the high-cost firm acts as a leader. The outputs under Stackelberg competition are higher than the outputs under Cournot competition because the leading firm produces more under Stackelberg than under Cournot to hinder entrants. High outputs are regarded as a strategy.

Accordingly, the implementation of the tax reduces the outputs of both firms. The tax reduces the outputs of high-cost firms more than the outputs of low-cost firms. When two firms respond at the same time, collecting water resource fees reduces outputs symmetrically. However, the implementation of a water resource tax has an asymmetric reduction effect on firms' output. In other cases, when two firms do not respond to the policy reform simultaneously, both policies have an asymmetric reduction effect on firms' outputs. However, the effect of taxes on the leading firm in such situations is more severe than the effect of taxes on the corresponding firm when they respond simultaneously.

\section{Concluding remarks}

This article addresses the effects of the "Fee-to-Tax" reform of China's water resources under an asymmetric duopoly. The impacting mechanisms of water resource taxes and water resource fees differ. Collecting water resource fees reduces the market size, while taxes amplify the weighted cost difference effects between industries. When all firms in the market respond to the policy simultaneously, the water resource fee reduces firms' outputs identically, while the water resource tax affects high-cost firms more than low-cost firms. Furthermore, when firms respond sequentially, the implementation of fees affects the equilibrium of firms asymmetrically. However, the tax affects the leading firm more than it affects the corresponding firm when all firms act synchronously. Additionally, the effect of the 
tax is more severe for leading firms than for followers. Surprisingly, it is also proven that the outputs are higher under Stackelberg competition than under Cournot competition because the leading firm under Stackelberg produces more than the leading firm under Cournot produces to hinder entrants. Therefore, the "Fee-to-Tax" reform provides some benefits to maintain the environmental development of some water-mining or related industries.

Based on the above analysis, taxes can act as an efficient regulative tool to support and shape industrial development. Some policy implications can be proposed according to the findings in this analysis. Specifically, the adoption of special taxes in some industries can help to eliminate backward production capacity. Because the collection of taxes has asymmetric effects on output, it works better to phase out backward production capacity than the collection of fees. Additionally, when the government decides a tax pattern, the market characteristics of different firms should be fully considered.

In this article, the effect of the "Fee-to-Tax" reform under an asymmetric duopoly with perfect information is discussed. Some further research topics arise. On the one hand, the market response under incomplete information is worth discussing. Incomplete information deters both government and industry decisions, and it is also important to study the mechanisms in such situations. On the other hand, in analyzing tax reforms, it is worth considering deterring the different production characteristics of different industries. In this way, an optimal tax regime can be proposed. It is crucial to design a tax regime that considers the long-term effects for some industries with externalities that involve energy, the environment and food safety.

\section{Declarations}

\section{Availability of data and materials}

Availability of data and materials was not suitable for this research.

\section{Competing interests}


All authors declare that there are no conflicts of interest.

\section{Funding}

This work is partially supported by the Guangdong Social Science Foundation (GD18JRZ05, GD17XYJ23), the National Natural Science Foundation of the People's Republic of China (71771057), the Innovative Foundation (Humanities and Social Sciences) for Higher Education of Guangdong Province (2017WQNCX053), the Guangdong Natural Science Foundation (2018A030310669), and the Project of Humanities and Social Sciences of the Ministry of Education of China (18YJC790156).

\section{Authors' contributions}

Pu-yan Nie conceived the idea and supervised the project. Zi-rui Chen designed the model, performed the mathematical studies and wrote the manuscript. All authors approved the manuscript before submission to the journal.

\section{Acknowledgements}

Appreciation is due to Prof. Bi-yu Peng and South China Normal University.

\section{References}

Acemoglu, D., Akcigit, U., Hanley, D., \& Kerr, W. (2016). Transition to clean technology. Journal of Political Economy, 124(1), 52-104.

Blackorby, C., \& Murty, S. (2007). Unit versus ad valorem taxes: Monopoly in general equilibrium. Journal of Public Economics, 91(3-4), 817-822.

Bloch, F., \& Demange, G. (2018). Taxation and privacy protection on Internet platforms. Journal of Public Economic Theory, 20(1), 52-66.

Changbo Qin, Yangwen Jia , Z. (Bob) Su , Hans T.A. Bressers \& Hao Wang (2012) The economic impact of water tax charges in China: a static computable general equilibrium analysis, Water International, 37:3, 279-292

Chen, Y. H., He, Q., \& Paudel, K. P. (2018). Quality competition and reputation of restaurants: the effects of capacity constraints. Economic research-Ekonomska 
istraživanja, 31(1), 102-118.

Chen, Y. H., Huang, S. J., Mishra, A. K., \& Wang, X. H. (2018). Effects of input capacity constraints on food quality and regulation mechanism design for food safety management. Ecological Modelling, 385, 89-95.

Chen, Y. H., Nie, P. Y., \& Wang, X. H. (2015). Asymmetric duopoly competition with innovation spillover and input constraints. Journal of Business Economics and Management, 16(6), 1124-1139.

Chen, Y. H., Wen, X. W., Wang, B., \& Nie, P. Y. (2017). Agricultural pollution and regulation: How to subsidize agriculture?. Journal of Cleaner Production, 164, 258-264.

Chen, Z. Y., \& Nie, P. Y. (2016). Effects of carbon tax on social welfare: A case study of China. Applied Energy, 183, 1607-1615.

Dixit, A. (1979). A model of duopoly suggesting a theory of entry barriers. The Bell Journal of Economics, 20-32.

Dong, B., Wei, W., Ma, X., \& Li, P. (2018). On the impacts of carbon tax and technological progress on China. Applied Economics, 50(4), 389-406.

Fuest, C., Peichl, A., \& Siegloch, S. (2018). Do higher corporate taxes reduce wages? Micro evidence from Germany. American Economic Review, 108(2), 393-418.

Griffith, R., Nesheim, L., \& O'Connell, M. (2018). Income effects and the welfare consequences of tax in differentiated product oligopoly. Quantitative Economics, 9(1), 305-341.

Golosov, M., Hassler, J., Krusell, P., \& Tsyvinski, A. (2014). Optimal taxes on fossil fuel in general equilibrium. Econometrica, 82(1), 41-88.

Häckner, J. (1999). A note on price and quantity competition in differentiated oligopolies. Department of economics, Stockholm University.

Häckner, J., \& Herzing, M. (2016). Welfare effects of taxation in oligopolistic markets. Journal of Economic Theory, 163, 141-166.

Hoffmann, M., \& Runkel, M. (2016). A welfare comparison of ad valorem and unit 
tax regimes. International Tax and Public Finance, 23(1), 140-157.

Lapan, H. E and Hennessy, D.A.(2011). Unit versus ad valorem taxes in multiproduct Cournot oligopoly. Journal of Public Economic Theory, 13(1):125- 138.

Li, M., Liu, C., \& Xu, S. (2019, May). Simulation and Analysis on the Optimal Tax Rate of Water Resources in Yunnan Province. In IOP Conference Series: Earth and Environmental Science (Vol. 267, No. 6, p. 062034). IOP Publishing.

Ma, Z., Zhao, J., \& Ni, J. (2018). Green Tax Legislation For Sustainable Development In China. The Singapore Economic Review, 63(04), 1059-1083.

Mattozzi, A., \& Snowberg, E. (2018). The right type of legislator: a theory of taxation and representation. Journal of Public Economics, 159, 54-65.

Mushtaq, S., Khan, S., Dawe, D., Hanjra, M. A., Hafeez, M., \& Asghar, M. N. (2008). Evaluating the impact of Tax-for-Fee reform (Fei Gai Shui) on water resources and agriculture production in the Zhanghe Irrigation System, China. Food Policy, 33(6), 576-586.

Nie, P. Y., \& Chen, Y. H. (2012). Duopoly competitions with capacity constrained input. Economic Modelling, 29(5), 1715-1721.

Nie, P. Y., Wang, C., Chen, Z. Y., \& Chen, Y. H. (2018). A theoretic analysis of key person insurance. Economic Modelling, 71, 272-278.

Qin, C., Jia, Y., Su, Z., Bressers, H. T., \& Wang, H. (2012). The economic impact of water tax charges in China: a static computable general equilibrium analysis. Water international, 37(3), 279-292.

Singh, N., \& Vives, X. (1984). Price and quantity competition in a differentiated duopoly. The RAND Journal of Economics, 546-554.

Skeath, S. E., \& Trandel, G. A. (1994). A Pareto comparison of ad valorem and unit taxes in noncompetitive environments. Journal of Public Economics, 53(1), 53-71.

Tao, A., Wang, X. H., \& Yang, B. Z. (2018). Duopoly models with a joint capacity constraint. Journal of Economics, 1-14.

Vetter, H. (2017). Commodity taxes and welfare under endogenous market 
conduct. Journal of Economics, 122(2), 137-154.

Vetter, H. (2014). Ad valorem versus unit taxes in oligopoly and endogenous market conduct. Public Finance Review, 42(4), 532-551.

Wang, C., Nie, P. Y., Peng, D. H., \& Li, Z. H. (2017). Green insurance subsidy for promoting clean production innovation. Journal of Cleaner Production, 148, 111-117.

Wang, X. H., \& Zhao, J. (2007). Welfare reductions from small cost reductions in differentiated oligopoly. International Journal of Industrial Organization, 25(1), 173-185.

Wang, X. H., \& Zhao, J. (2009). On the efficiency of indirect taxes in differentiated oligopolies with asymmetric costs. Journal of Economics, 96(3), 223-239.

Wang, Z., \& Wright, J. (2017). Ad valorem platform fees, indirect taxes, and efficient price discrimination. The RAND Journal of Economics, 48(2), 467-484.

Yang, Y. C., Nie, P. Y., Liu, H. T., \& Shen, M. H. (2018). On the welfare effects of subsidy game for renewable energy investment: Toward a dynamic equilibrium model. Renewable Energy, 121, 420-428.

\section{Appendix}

A.

By virtue of (4) and the assumption of $c_{A}<c_{B}$, we have the following formulation:

$q_{A}^{*, 1}+q_{B}^{*, 1}=\frac{(2-\gamma)(1-\tau) \alpha-\left(2 c_{A}-\gamma c_{B}\right)}{\left(4-\gamma^{2}\right)(1-\tau)}+\frac{(2-\gamma)(1-\tau) \alpha-\left(2 c_{B}-\gamma c_{A}\right)}{\left(4-\gamma^{2}\right)(1-\tau)}$

$=\frac{2(2-\gamma) \alpha}{\left(4-\gamma^{2}\right)}-\frac{\left(c_{B}+c_{A}\right)(2-\gamma)}{\left(4-\gamma^{2}\right)(1-\tau)}$

$=\frac{2 \alpha}{(2+\gamma)}-\frac{\left(c_{B}+c_{A}\right)}{(2+\gamma)(1-\tau)}$.

Thus, the total outputs in this industry decrease with ad valorem taxes. Moreover, 
the formulation of output gap $\Delta q^{*, 1}=\frac{c_{B}-c_{A}}{(2-\gamma)(1-\tau)}$ along with $c_{A}<c_{B}$ yields that an ad valorem tax increases the output gap.

Furthermore, under a low cost difference, we have $2 c_{A}-\gamma c_{B}>0$, and then, (9) and (12) indicate that ad valorem taxes reduce the outputs and profits of both firms.

Under a large cost difference or when $2 c_{A}-\gamma c_{B}<0$ holds, (9) and (12) show that ad valorem taxes improve the outputs and profits of high-efficiency firms while reducing the outputs and profits of low-efficiency firms.

The conclusions are achieved, and the proof is complete.

B.

Function (10) implies that the output difference increases with the intensity of ad valorem taxes. Obviously, (5) shows that the output difference is not affected by the intensity of unit taxes. The first part of the Proposition is proved.

We further prove the second part. For the outputs of firms, we first show $\kappa \geq \frac{\tau\left(2 c_{A}-\gamma c_{B}\right)}{(2-\gamma)(1-\tau)} \quad$ and $\quad \kappa \leq \frac{\tau\left(2 c_{B}-\gamma c_{A}\right)}{(2-\gamma)(1-\tau)} \quad$ based $\quad$ on $\quad$ (8). We first show $\kappa \geq \frac{\tau\left(2 c_{A}-\gamma c_{B}\right)}{(2-\gamma)(1-\tau)}$ by contradiction. If $\kappa \geq \frac{\tau\left(2 c_{A}-\gamma c_{B}\right)}{(2-\gamma)(1-\tau)}$ does not hold, then we have the relationship $\kappa<\frac{\tau\left(2 c_{A}-\gamma c_{B}\right)}{(2-\gamma)(1-\tau)}$. Moreover, $\kappa<\frac{\tau\left(2 c_{A}-\gamma c_{B}\right)}{(2-\gamma)(1-\tau)} \leq \frac{\tau\left(2 c_{B}-\gamma c_{A}\right)}{(2-\gamma)(1-\tau)}$. On the one hand, based on (9) and (4), we then have $q_{A}^{*, 1}+q_{B}^{*, 1}>q_{A}^{*, 2}+q_{B}^{*, 2}$. On the other hand, we have $\left(q_{A}^{*, 1}+q_{B}^{*, 1}\right)-\left(q_{A}^{*, 2}+q_{B}^{*, 2}\right)=\frac{2 \kappa}{(2+\gamma)}-\frac{\tau\left(c_{A}+c_{B}\right)}{(2+\gamma)(1-\tau)}$. Furthermore, $\left(q_{A}^{*, 1}+q_{B}^{*, 1}\right)-\left(q_{A}^{*, 2}+q_{B}^{*, 2}\right)=\frac{2 \kappa}{(2+\gamma)}-\frac{\tau\left(c_{A}+c_{B}\right)}{(2+\gamma)(1-\tau)}$ 


$$
\begin{aligned}
& \leq \frac{2}{(2+\gamma)} \frac{\tau\left(2 c_{A}-\gamma c_{B}\right)}{(2-\gamma)(1-\tau)}-\frac{\tau\left(c_{A}+c_{B}\right)}{(2+\gamma)(1-\tau)} \\
& =\frac{\tau\left[4 c_{A}-2 \gamma c_{B}-(2-\gamma)\left(c_{A}+c_{B}\right)\right]}{(2+\gamma)(2-\gamma)(1-\tau)}=\frac{\tau(2+\gamma)\left(c_{A}-c_{B}\right)}{(2+\gamma)(2-\gamma)(1-\tau)}<0 .
\end{aligned}
$$

The above first inequality comes from $\kappa<\frac{\tau\left(2 c_{A}-\gamma c_{B}\right)}{(2-\gamma)(1-\tau)}$, and the second inequality is achieved from the assumption of $c_{A}<c_{B}$.

This is contradicted with the above formulation $q_{A}^{*, 1}+q_{B}^{*, 1}>q_{A}^{*, 2}+q_{B}^{*, 2}$. Therefore, $\kappa \geq \frac{\tau\left(2 c_{A}-\gamma c_{B}\right)}{(2-\gamma)(1-\tau)}$ holds. (15) and $\kappa \geq \frac{\tau\left(2 c_{A}-\gamma c_{B}\right)}{(2-\gamma)(1-\tau)}$ manifest $q_{A}^{*, 1} \geq q_{A}^{*, 2}$. Similarly, we have the relationship of $\kappa \leq \frac{\tau\left(2 c_{B}-\gamma c_{A}\right)}{(2-\gamma)(1-\tau)} . \quad \kappa \leq \frac{\tau\left(2 c_{B}-\gamma c_{A}\right)}{(2-\gamma)(1-\tau)}$ and (15) yield $q_{B}^{*, 1} \leq q_{B}^{*, 2}$

Moreover, (15) and $c_{A}<c_{B}$ manifest $q_{A}^{*, 1}-q_{A}^{*, 2}>q_{B}^{*, 1}-q_{B}^{*, 2}$. Thus, the second part is immediately proved.

We further address the total outputs. On the one hand, we have $q_{A}^{*, 1}+q_{B}^{*, 1}=\frac{2(1-\tau) \alpha-\left(c_{A}+c_{B}\right)}{(2+\gamma)(1-\tau)}$. On the other hand, we obtain the following relationship: $q_{A}^{*, 2}+q_{B}^{*, 2}=\frac{2(\alpha-\kappa)-\left(c_{A}+c_{B}\right)}{(2+\gamma)}$. Therefore, by direct calculation, we immediately have $\left(q_{A}^{*, 1}+q_{B}^{*, 1}\right)-\left(q_{A}^{*, 2}+q_{B}^{*, 2}\right)=\frac{2 \kappa}{(2+\gamma)}-\frac{\tau\left(c_{B}+c_{A}\right)}{(2+\gamma)(1-\tau)}$.

According to the above analysis, we have $\frac{\tau\left(2 c_{B}-\gamma c_{A}\right)}{(2-\gamma)(1-\tau)} \geq \kappa \geq \frac{\tau\left(2 c_{A}-\gamma c_{B}\right)}{(2-\gamma)(1-\tau)}$. Based on (13) and (14), we further consider the total outputs in three cases as follows. 
Case 1. Under $\kappa \leq \tau p_{A}^{*, 1}<\tau p_{B}^{*, 1}$ or $\frac{\kappa}{\tau} \leq \frac{\alpha}{2+\gamma}+\frac{\left(2-\gamma^{2}\right) c_{A}+\gamma c_{B}}{\left(4-\gamma^{2}\right)(1-\tau)}$, from (13) and (14), we immediately have the following relationship: $\left(q_{A}^{*, 1}+q_{B}^{*, 1}\right)-\left(q_{A}^{*, 2}+q_{B}^{*, 2}\right)=\frac{2 \kappa}{(2+\gamma)}-\frac{\tau\left(c_{B}+c_{A}\right)}{(2+\gamma)(1-\tau)}<0$. or $\frac{\kappa}{\tau} \leq \frac{\left(c_{B}+c_{A}\right)}{2(1-\tau)}$.

Case 2. Under $\quad \tau p_{B}^{*, 1} \geq \kappa \geq \tau p_{A}^{*, 1} \quad$ or the formulation $\frac{\alpha}{2+\gamma}+\frac{\left(2-\gamma^{2}\right) c_{A}+\gamma c_{B}}{\left(4-\gamma^{2}\right)(1-\tau)} \leq \frac{\kappa}{\tau} \leq \frac{\alpha}{2+\gamma}+\frac{\left(2-\gamma^{2}\right) c_{B}+\gamma c_{A}}{\left(4-\gamma^{2}\right)(1-\tau)}$, we immediately have the relationship $\left(q_{A}^{*, 1}+q_{B}^{*, 1}\right)-\left(q_{A}^{*, 2}+q_{B}^{*, 2}\right)=\frac{2 \kappa}{(2+\gamma)}-\frac{\tau\left(c_{B}+c_{A}\right)}{(2+\gamma)(1-\tau)}>0$. Or $\frac{\kappa}{\tau} \geq \frac{\left(c_{B}+c_{A}\right)}{2(1-\tau)}$.

We also show that it is impossible for the relationship $\left(q_{A}^{*, 1}+q_{B}^{*, 1}\right)-\left(q_{A}^{*, 2}+q_{B}^{*, 2}\right)=\frac{2 \kappa}{(2+\gamma)}-\frac{\tau\left(c_{B}+c_{A}\right)}{(2+\gamma)(1-\tau)} \leq 0$. or $\frac{\kappa}{\tau} \leq \frac{\left(c_{B}+c_{A}\right)}{2(1-\tau)}$. In contrast, $\frac{\alpha}{2+\gamma}+\frac{\left(2-\gamma^{2}\right) c_{A}+\gamma c_{B}}{\left(4-\gamma^{2}\right)(1-\tau)} \leq \frac{\kappa}{\tau}$, and we have $\frac{\alpha}{2+\gamma}+\frac{\left(2-\gamma^{2}\right) c_{A}+\gamma c_{B}}{\left(4-\gamma^{2}\right)(1-\tau)}-\frac{\left(c_{B}+c_{A}\right)}{2(1-\tau)}$
$=\frac{\alpha}{2+\gamma}-\frac{\gamma^{2} c_{A}+\left(4-\gamma^{2}-2 \gamma\right) c_{B}}{2\left(4-\gamma^{2}\right)(1-\tau)}>0$.

The above inequality comes from $c_{A}<c_{B}$ and $q_{B}^{*, 1}>0$. Thus, it is impossible for $\left(q_{A}^{*, 1}+q_{B}^{*, 1}\right)-\left(q_{A}^{*, 2}+q_{B}^{*, 2}\right)=\frac{2 \kappa}{(2+\gamma)}-\frac{\tau\left(c_{B}+c_{A}\right)}{(2+\gamma)(1-\tau)} \leq 0 \quad$ under Case 2.

Case 3. Under $\quad \kappa \geq \tau p_{B}^{*, 1} \geq \tau p_{A}^{* 1} \quad$ or $\quad \kappa \geq \tau\left[\frac{\alpha}{2+\gamma}+\frac{\left(2-\gamma^{2}\right) c_{B}+\gamma c_{A}}{\left(4-\gamma^{2}\right)(1-\tau)}\right]$, we immediately have the relationship $\left(q_{A}^{*, 1}+q_{B}^{*, 1}\right)-\left(q_{A}^{*, 2}+q_{B}^{*, 2}\right)=\frac{2 \kappa}{(2+\gamma)}-\frac{\tau\left(c_{B}+c_{A}\right)}{(2+\gamma)(1-\tau)}>0$. or $\frac{\kappa}{\tau} \geq \frac{\left(c_{B}+c_{A}\right)}{2(1-\tau)}$.

Therefore, the third part is proved, and the conclusions are achieved. 
C.

From (22) and (9), we have

$$
\begin{aligned}
& q_{A}^{*{ }_{s, 1}}-q_{A}^{*, 1}=\frac{(2-\gamma)(1-\tau) \alpha-\left(2 c_{A}-\gamma c_{B}\right)}{2\left(2-\gamma^{2}\right)(1-\tau)}-\frac{(2-\gamma)(1-\tau) \alpha-\left(2 c_{A}-\gamma c_{B}\right)}{\left(4-\gamma^{2}\right)(1-\tau)} \\
& =\frac{(2-\gamma)(1-\tau) \alpha-\left(2 c_{A}-\gamma c_{B}\right)}{2\left(2-\gamma^{2}\right)(1-\tau)\left(4-\gamma^{2}\right)}\left[\left(4-\gamma^{2}\right)-2\left(2-\gamma^{2}\right)\right] \\
& =\frac{(2-\gamma)(1-\tau) \alpha-\left(2 c_{A}-\gamma c_{B}\right)}{2\left(2-\gamma^{2}\right)(1-\tau)\left(4-\gamma^{2}\right)} \gamma^{2}>0 .
\end{aligned}
$$

Therefore, we have $q_{A}^{*, 1}>q_{A}^{*, 1}$.

$$
\begin{aligned}
& q_{B}^{* s, 1}-q_{B}^{*, 1}=\frac{\left[\left(4-2 \gamma-\gamma^{2}\right)\left(4-\gamma^{2}\right)-4(2-\gamma)\left(2-\gamma^{2}\right)\right](1-\tau) \alpha+\left[8\left(2-\gamma^{2}\right)-\left(4-\gamma^{2}\right)^{2}\right] c_{B}+2 \gamma^{3} c_{A}}{4\left(2-\gamma^{2}\right)(1-\tau)\left(4-\gamma^{2}\right)} \\
& =\gamma^{3} \frac{(\gamma-2)(1-\tau) \alpha-\gamma c_{B}+2 c_{A}}{4\left(2-\gamma^{2}\right)(1-\tau)\left(4-\gamma^{2}\right)}<0 .
\end{aligned}
$$

The above inequality comes from $q_{A}^{* 1}>0$ yielding $(\gamma-2)(1-\tau) \alpha-\gamma c_{B}+2 c_{A}<0$.

Therefore, we immediately have the relationship $q_{B}^{* s, 1}<q_{B}^{*, 1}$. Thus, the output difference is larger under Stackelberg competition than under Cournot competition.

The conclusions are achieved, and the proof is complete.

D.

Obviously, we have $q_{A}^{*_{s, 3}}<q_{A}^{*, 1}<q_{A}^{*_{s, 1}}$ and $q_{B}^{*_{s, 3}}>q_{B}^{*, 1}>q_{B}^{*_{s, 1}}$. Here, we compare the total outputs under the three cases.

$$
\begin{aligned}
& q_{A}^{*_{s, 3}}+q_{B}^{*_{s, 3}}=\frac{\left(8-4 \gamma-\gamma^{2}\right)(1-\tau) \alpha-(4-2 \gamma) c_{B}-\left(4-\gamma^{2}-2 \gamma\right) c_{A}}{4\left(2-\gamma^{2}\right)(1-\tau)}, \\
& q_{A}^{*, s 1}+q_{B}^{*, s 1}=\frac{\left(8-4 \gamma-\gamma^{2}\right)(1-\tau) \alpha-\left(4-\gamma^{2}-2 \gamma\right) c_{B}-(4-2 \gamma) c_{A}}{4\left(2-\gamma^{2}\right)(1-\tau)} . \\
& q_{A}^{*, 1}+q_{B}^{*, 1}=\frac{(4-2 \gamma)(1-\tau) \alpha-(2-\gamma)\left(c_{A}+c_{B}\right)}{\left(4-\gamma^{2}\right)(1-\tau)} .
\end{aligned}
$$


$c_{B}>c_{A}$ and $4-\gamma^{2}-2 \gamma<4-2 \gamma$ imply that $q_{A}^{* s, 1}+q_{B}^{* s, 1}>q_{A}^{* s, 3}+q_{B}^{*, 3}$. Furthermore,

$$
\begin{aligned}
& \left(q_{A}^{*, 1}+q_{B}^{*, 1}\right)-\left(q_{A}^{*, s 1}+q_{B}^{*, s 1}\right)=\frac{-\gamma^{2}\left(4-4 \gamma+\gamma^{2}\right)(1-\tau) \alpha-\gamma^{3}(2-\gamma) c_{A}+2 \gamma^{2}(2-\gamma) c_{B}}{4\left(2-\gamma^{2}\right)\left(4-\gamma^{2}\right)(1-\tau)} \\
& =-\gamma^{2}(2-\gamma) \frac{(2-\gamma)(1-\tau) \alpha+\gamma c_{A}-2 c_{B}}{4\left(2-\gamma^{2}\right)\left(4-\gamma^{2}\right)(1-\tau)}<0 .
\end{aligned}
$$

The above inequality comes from $q_{B}^{*, 1}>0$. Similarly, we have

$$
\left(q_{A}^{*, 1}+q_{B}^{*, 1}\right)-\left(q_{A}^{*, s 3}+q_{B}^{*, s 3}\right)=-\gamma^{2}(2-\gamma) \frac{(2-\gamma)(1-\tau) \alpha+\gamma c_{B}-2 c_{A}}{4\left(2-\gamma^{2}\right)\left(4-\gamma^{2}\right)(1-\tau)}<0 .
$$

The conclusions are achieved, and the proof is complete. 